state of the art for possible palliatives or alternatives), this is an excellent and authoritative, comprehensive reference. JAMES HAy STEVENS

\section{Elmer Sperry}

Elmer Sperry: Inventor and Engineer. By Thomas Parke Hughes. Pp. xvii+ 348. (Johns Hopkins: Baltimore and London, November 1971.) \$15; £7.15.

THIS is a comprehensive and wellwritten story of a remarkable American who, born in November 1860 , spent an incredibly active life in patenting and exploiting over 350 inventions through a most unusual combination of technical and commercial skills.

His father seems to have taken little interest in him as a child, and as his mother died within a few hours of his birth he was brought up in the home of his grandparents at Cortland, a village twenty miles north-east of Ithaca. Here, while attending the local school, his interest in all things mechanical or electrical made him a welcome visitor in the local engineering concerns. The Cortland Waggon Company turning out thousands of horse-drawn vehicles annually was destined to play an important part in young Sperry's life during the next few years.

The name Sperry is of course mainly associated throughout the world with the numerous practical applications of the gyroscope but the author has shown that in his early years he played a prominent part in the development of electrical engineering in the United States, a fact which is often overlooked. At a time when Edison, Elihu Thomson, Houston and others were making great strides in this field, Elmer Sperry in his teens was producing original ideas in the design of arc lamps and generators and carrying out extensive distribution systems with financial support from established industrialists convinced of his originality and flair for putting his ideas into practice.

About this time he made contact with a professor at Cornell University and helped him in the construction of a Gramme dynamo, with the result that he made his first invention, a governor to control the voltage of the machine, and soon afterwards obtained his first patent. Within a few months he was making an intense study of all electrical patents as they came out and applying his teeming brain to improvements on the ideas disclosed. He soon discovered, however, that there was much more in the patent field than the ability to design and construct: he became involved in a legal battle with one of the rapidly growing competitors. He came out "on top", however. He was successful at 23 in securing support to found a company bearing his name with a capital of a million dollars with a salary and proportion of the profits. Major projects followed, an outstanding example being the original Chicago central generating station. This was accompanied by a spate of trouble with the telephone authorities through leakage from his underground cables and at 25 he was calling together other undertakers to form NELA for pooling these problems.

At 27 Sperry found time to marry and in due course produced a family of three boys who became distinguished successors to their father and a daughter who cooperated in his patent activities. His interests spread rapidly and magnificently through street cars, electric locomotives, gas engines, electrically propelled vehicles and, on an even grander scale, the growing field of electro-chemistry.

It was not until he had reached the age of 50 that Sperry became interested in the developments of the gyroscope. $\mathrm{He}$ formed one more company, then restricted his time to research and development. He became young once more and through his energetic efforts created a monopoly resulting in 10,000 dollar orders from the American and other navies for his sophisticated and original gyrostabilizer and gyrocompass. The account of his timely entry and success in this field reads like a fairy tale but the chapter devoted to the theory of the various devices would alone constitute an excellent introduction to the subject for any student aiming at a doctorate.

No reviewer of this delightful book could avoid paying a high compliment to the author for the wealth of illustrations which he has succeeded in bringing together and for his enthusiasm which comes through on every page and appropriately matches the great character of his subject. Percy Dunsheath

\section{Sound Made Visible}

Seeing Sound. By Winston E. Kock. Pp. vii +93. (Wiley: New York and London, February 1972.) $£ 3.75$.

THE title and a quick glance at some of the photographs in this book excited considerable interest but on closer inspection I found it extremely puzzling and I cannot really envisage the readership for which it is written. This does not mean to say, however, that it is of no value. The first chapter is a very elementary introduction to the nature of sound and then in chapters 2 and 3 we meet perhaps the most interesting section describing a simple microphone-lamp method of scanning a sound field and making the shapes of radiated beams, or of interfering beams, literally visible in a photograph. The technique of revealing phase differences is particularly interesting, though simple, and the photographs illustrating this chapter justify the title of the book quite well. These chapters might form a useful source of ideas for student experimental projects. Chapters 4 and 5 are fairly conventional accounts of soundspectrograph techniques used in the study of speech. They are copiously illustrated and would provide a useful source of illustrations for general lectures. Chapter 6 is devoted to a $\mathrm{mix}$ ture of items which, on the whole, are more concerned with developments in electronic organs than with visual presentation and the final chapter skims rapidly over auto-correlation functions, acoustic holography and the directive properties of loudspeakers.

The overall impression is thus that some very good ideas and quite a number of excellent and interesting photographs have been made the excuse for a book but the remaining material added to make the size acceptable does not come up to the same standard and is treated somewhat superficially.

\section{A. TAYLOR}

\section{Unobjective Test}

\section{Objective Personality Assessment: Changing Perspectives. Edited by} James N. Butcher. Pp. $x+212$. (Academic: New York and London, August 1972.) \$6.95.

THIS book, we are told, "will be invaluable to all those who work with personality testing-including psychologists, clinicians, psychiatrists, educators, sociologists and social workersas well as to researchers in the field of personality". Not so. It is difficult to think of anybody who would really benefit very much from reading this slight and misleadingly entitled volume. The book does not deal with objective personality assessment at all; it is concerned essentially with the Minnesota Multiple Personality Inventory (MMPI) and should have been entitled accordingly. Five of the seven chapters published in this volume are based on invited addresses at the Fifth Annual Symposium on Recent Developments in the Use of the MMPI; thus the book sails under a false flag, and readers attracted by the title will be sadly disappointed-even though such contributors as Meehl can hardly help writing interestingly and well, and producing thought-provoking comments.

The MMPI is certainly a widely used test, and if one had to choose between it and such projective measures as the Rorschach, TAT, or the reading of tea leaves, one would probably come down in favour of the MMPI. Yet the reason for its existence has always been 